\title{
The Understanding of Pediatric Akinetic Mutism
}

\author{
Luiz Severo Bem Jr. ${ }^{1,2}$, Júlia Gemir ${ }^{3}$, Renata R. M. Cysneiros ${ }^{4}$, Hildo C. Azevedo ${ }^{4}$ \\ 1. Neurological Surgery, Hospital da Restauração, Recife, BRA 2. Neuroscience Post-Graduate Program, Federal \\ University of Pernambuco, Recife, BRA 3. Neurological Surgery, University of Pernambuco, Recife, BRA 4. Neurological \\ Surgery, Restauração Hospital, Recife, BRA
}

Corresponding author: Luiz Severo Bem Jr., luizseverojunior@yahoo.com.br

\begin{abstract}
Pediatric akinetic mutism syndrome is a clinical disease resulting from cerebellar injury and characterized by the absence of speech or reduced speech, emotional lability, there may also be hypotonia, oropharyngeal dysfunction/dysphagia, bladder and intestinal incontinence, or other behavioral disorders and neurological signals. It is described as the most recurrent complication in children, after posterior fossa tumor surgery, mainly related to cerebellar midline injuries. An increasing number of research and prospective reviews have provided valuable information on cerebellar mutism syndrome in recent years. The purpose of this review was to elucidate the pathophysiological basis and the predictive factors for this syndrome. Most cases of mutism are due to injury cerebellar tracts and cerebellar-cerebral circuits, involving particularly distinct points of the dentate-thalamus-cortical and dentato-rubro-thalamus-cortical. Advanced neuroimaging techniques, such as tractography and perfusion studies, have contributed to demonstrating changes in these pathways in patients with pediatric cerebellar mutism.
\end{abstract}

Categories: Neurology, Pediatrics, Neurosurgery

Keywords: akinetic mutism, pediatric akinetic mutism, pathophysiology, dentate nucleus

\section{Introduction And Background}

According to the new studies, the current characteristics of mutism can be defined as delayed onset mutism/reduced speech and emotional lability. Additional features may include hypotonia, oropharyngeal dysfunction/dysphagia, bladder and bowel incontinence, or other behavioral and neurological disturbances $[1,2]$.

Posterior fossa surgical access is one of the most prevalent in children. This access is related to akinetic mutism (AM). Mutism cases are related in the age range from two to ten years. Moreover, it is known as the most common histological type of tumor of the posterior fossa is medulloblastoma $[3,4]$.

Received 07/14/2020 Review began 08/07/2020 Review ended 01/08/2021 Published 01/09/2021

○ Copyright 2021

Severo Bem et al. This is an open access article distributed under the terms of the Creative Commons Attribution License CC-BY 4.0., which permits unrestricted use, distribution, and reproduction in any medium, provided the original author and source are credited.
Because of the uncertainties regarding the pathophysiological basis of mutism, the main hypotheses have been used over the years. Currently, the involvement of the dentate-thalamus-cortical (DTC) circuit is more accepted, related to disturbance of cerebellum-cerebral. About the mechanism of this disturbance, axons of dentate nucleus leave the cerebellum through the superior cerebellar peduncle, then decussate in the midbrain, reach the thalamus, and, finally project to the cortex (e.g., prefrontal, temporal, and parietal). Damage leading to AM (akinetic mutism) can occur anywhere along the tract. However, given a close relationship with posterior fossa surgery, it is more likely to involve initial parts (e.g., dentate nucleus or superior cerebellar peduncle). The pathophysiological basis of akinetic mutism has not been fully elucidated and there are several controversies [4-6].

Briefly, the goal of this article is to clarify the pathophysiological bases of pediatric akinetic mutism in order to detail its symptoms and its predictive factors.

\section{Review}

Cerebellar mutism (CM) usually develops more in children than adults, after posterior fossa surgery. This condition does not usually appear immediately after surgery but after hours or days. The fact that mutism is a transient condition, it can resolve itself in a period between four and six weeks to a few months. In addition, mutism generates cognitive and behavioral disorders in the patient, and some consequences may persist in view of the persistence of CM [7]. Table 1 provides a summary of articles on the topic in recent years.

\begin{tabular}{|c|c|c|c|}
\hline Author/Year & Objectives & Methods & Conclusions \\
\hline da Silveira & $\begin{array}{l}\text { Describe and analyze a case } \\
\text { report to assess the signs and }\end{array}$ & & $\begin{array}{l}\text { Case report of an eight-year-old patient with medulloblastoma who developed } \\
\text { posterior fossa syndrome after surgical intervention. Therefore, as PFS can } \\
\text { cause drastic and eventually disabling changes, and its pathophysiology }\end{array}$ \\
\hline
\end{tabular}




\section{Cureus}

\section{et al., 2017 symptoms that the patient [8] developed with PFS. Case report of one patient. \\ Arnts et al., 2020 [9] \\ Describe the pathophysiology of the disease and its treatment. \\ Describe a case report of a pediatric patient who developed cerebellar mutism after neurosurgery. In the report, he points out \\ Nicita et al., 2016 [4] medications for the treatment of this condition. For this, he also seeks to describe the pathophysiology of the disease. Case report of one patient.}

Describe 11 pediatric patients

Tovarwith tumors. One of them

Spinoza and presented akinetic mutism Choi, 2016 and the patient's symptoms. [10] Description of 11 patients, including one with mutism.

Describe the case of a pediatric patient with humoral immunity deficiency who presented lethargic

Yang et al., encephalitis with isolated 2015 [11] lesions of black matter on magnetic resonance imaging followed by the second encephalitis associated with akinetic mutism. Case Report of one patient.

Describe a case report of a pediatric patient with mumps who contracted mumps Suga et al., encephalitis. It also shows 2015 [12] mutism and this condition is described in the report. Case report of one patient.

Description and study of bilateral paramedical thalamic

\section{Kamas̄ak et infarctions and their}

al., 2015 [13] involvement in pediatric patients. Two patients were analyzed.

The article reports on a case of transient cerebellar mutism

Pinheiro et al., 2012 [14] in a four-year-old child resection of an ependymoma from the posterior fossa.
Case Report. suggestive of injury to the toothed nucleus and/or its efferents, it is imperative to recognize this condition and exclude other operative complications. That said, the treatment is favorable.

$\mathrm{AM}$ is a rare but serious neurological disorder. Patients with AM do not have the motivating vector for the expression of the spontaneous mechanism, behavior, and speech. This results in almost complete dependence on others for the simplest activities of everyday life, constantly leading to nursing at home.

The pathophysiological basis of PPCMS has not yet been fully elucidated and there are several controversies and the current hypothesis is that PPCMS is related to cerebral circuit disturbance involving particularly the thalamus-cortical toothed pathway. Concluding the objective of the study, this single patient does not allow to conclude the company, and this study should be replicated in a large sample of PPCMS in the postoperative period in pediatrics and adult to understand whether benzodiazepines can play an effective role in the treatment of this condition.

Patient 7, who had NF1 and thalamic pilocytic astrocytoma of the middle brain, experienced acute edema after severe ablation that caused dense hemiparesis, akinetic mutism, and eye movement disorder. Our hypothesis is that overheating of the 2D target area and the longer ablation time contributed to the conductive heating of the peritumoral tissue. The patient presented concomitant hyponatremia and fluid overload during the operation. Since then, we have carefully monitored these parameters intraoperative period. This patient was treated with greater steroid dosages $(1 \mathrm{mg} / \mathrm{kg} / \mathrm{day})$ and $\mathrm{NaCl}$ at $3 \%$. Steroids decreased two weeks after surgery. The patient showed progressive improvement after rehabilitation and, 18 months after ablation, presented only mild residual weakness in the hands and dysarthria.

He presented drowsiness, Parkinson's syndrome (facial mask, akinetic mutism, tremor, stiffness), ophthalmoplegia, and nystagmus, meeting the diagnostic criteria for lethargic encephalitis. Laboratory tests showed pleocytosis and a

Case Report. positive oligoclonal band in CSF, consistent with other reports. The lesion of the black substance can inhibit the activity of the cortex, reducing dopaminergic entry into the striated ganglion-thalamus circuit of the cortex, which explains Parkinson's syndrome in this patient.

Symptoms of neurological disturbance varied widely in this case. We considered that akinesia and mutism originated from the lesion of the basal ganglia, while hypothalamic injury caused disturbances in the accommodation of body temperature, blood pressure, and heart rate.

Bilateral paramedian thalamus infarctions can result in many diseases and Clinical damage. Common clinical manifestations include disorientation, confusion, Observations. hypersolence, deep coma, and "coma wake", or akinetic mutism (lack of response), in addition to severe memory impairment.

Case Report

This case adds to the few hitherto reported cases in the literature of this unusual complication of the subsequent fossa surgery in children.

TABLE 1: Summary of studies related to pediatric akinetic mutism. 


\section{Cureus}

After surgical procedures, edema and regions of ischemia in organs are normal due to manipulation and trauma caused by the surgery. Thus, it is justified the latency of mutism to manifest, usually taking 24-48 hours to appear the first symptoms. Furthermore, those edema and ischemia would be located in certain regions of the brain that would trigger the symptoms of akinetic mutism [15].

Over the years, studies concerning the pathophysiology of akinetic mutism have been modified. The medical literature has presented many studies addressing the origin of cerebellar mutism. Thus, researches involving the affected dentate nucleus and the complex involvement of the vermis region have been widely discussed and validated in medical sciences for years. However, nowadays, the dentato-thalamo-cortical tract can better elucidate the pathophysiology of the syndrome, being the most accepted study today.

Initially, it was believed that the development of this condition was due to the involvement of the dentate nucleus. After some studies, it was understood that isolated lesions, in this context, the cerebellar ones, would not be able to provoke all the symptoms of akinetic mutism. After discarding the previous hypothesis, it was understandable to look for lesions on both sides of the cerebellum; however, after studies, mutism would be triggered, even if there was no bilateral cerebellar lesion [16].

Later studies associated mutism with lesions in the vermis region, without necessarily having bilateral cerebellar lesion. A fact evidenced in a case study, in which CM that was associated with atrophy of the vermis on MRI and decreased blood flow in the same region on the SPECT (single photon emission computed tomography) scan, and suggested that CM resulted from injury to the vermis with or without a bilateral cerebellar hemisphere lesion $[17,18]$.

Other studies used to believe that the vermis would be the main reason for the symptoms associated with mutism. Nevertheless, if this region were really the only one responsible for the development of CM, this condition would be much more incident and more persistent, which is not true, since the acute manifestations of the disease do not last more than months. This theory was discarded, transferring the reasoning to the possible hypothesis that mutism is not triggered due to the involvement of a single area of the brain, but of a set of brain areas $[19,20]$.

So today, one of the most accepted and persistent theories about the pathophysiology of CM involves the dentato-thalamus-cortical tract. The anatomophysiology of this tract can be described through the course to and from the dentate nucleus of the cerebellum in any region, travels through the superior cerebellar peduncle, crosses the midline to the opposite part within the decussation of the superior cerebellar peduncle, continues through the brainstem to the contralateral ventrolateral nucleus of the thalamus and later to the contralateral cerebral motor cortex (premotor and supplementary motor cortices). The manifestations resulting from mutism are caused by injuries in the course of that tract. When we relate these structures to the posterior fossa surgery, the one that most causes CM in patients, it is possible to notice that proximal parts of the treatment are most affected. Thereafter, regions such as the dentate nucleus, cerebellar peduncles, and/or brainstem connections are closely correlated with the pathophysiology of akinetic mutism [21].

The injuries along the DTC tract cannot be just anatomical injuries along the tract. So, it was necessary to look for another mechanism to justify the involvement of CM symptoms. Thus, cerebellum-cerebral diaschisis can elucidate the pathophysiology of mutism, since this diaschisis corresponds to the functional inhibition of a certain region of the brain, in which that region is connected, through transsynaptic neural pathways, to the area of the primary lesion. It can justify the appearance of symptoms characteristic of brain regions that were not even surgically injured initially [22].

Some hypotheses can confirm this theory, since these cerebellar areas were subjected to imaging techniques that prove the relative loss of physiological function in the affected region, without necessarily having visible damage. It is possible to infer that the lesions may appear before or after the surgery, in which the edema and the vasospasm during and after the surgical procedure, can cause damage to the adjacent venous circulation. Therefore, AM can persist in its clinical presentation until the edema and vasospasm are resolved $[23,24]$.

On the basis of these theories, visible radiological ends up in some studies, a study presented results that were found in patients who developed the post-operative cerebellar mutism syndrome. Post-operative brain MRI usually shows signal abnormalities within the superior cerebellar peduncles and dentate nuclei: T2 hyperintense signal within the superior cerebellar peduncles and dentate nuclei. Furthermore, MR tractography - can show disruption of the dentate-thalamus-cortical tract $[25,26]$.

Trasnvermian approach is a common route of access to fourth ventricle tumors but with the risk of important morbidity. Several approaches have been recognized to reduce morbidity; some of which include 
transforaminal, subtonsillar, telovelar approaches, etc. These approaches are devised on the basis that accurate dissection along the natural avascular planes will avoid lesion to the significant structures in this location minimizing morbidity. Therefore, a clear understanding of the posterior fossa anatomy was supposed to facilitate dissection and provide better outcomes. Yet, a significant incidence of postoperative mutism is still seen with this approach in large tumors. One theory could be that because the mutism is a disturbance of cerebellum-cerebral circuitry particularly involving the dentato-thalamus-cortical, and not only from a compromised area of the brain [27,28].

\section{Conclusions}

The pathophysiological basis of postoperative pediatric cerebellar mutism syndrome (PPCMS) is better correlated nowadays with the involvement of the dentato-thalamus-cortical tract. Even with the evolution of microsurgical technique, mutism is still a condition that continues to affect children who perform these surgeries and posterior fossa surgery. Selection of the less risky surgical approaches could be reached by elaborated studies of advanced neuroimaging and solid knowledge of the surrounding anatomy.

\section{Additional Information \\ Disclosures}

Conflicts of interest: In compliance with the ICMJE uniform disclosure form, all authors declare the following: Payment/services info: All authors have declared that no financial support was received from any organization for the submitted work. Financial relationships: All authors have declared that they have no financial relationships at present or within the previous three years with any organizations that might have an interest in the submitted work. Other relationships: All authors have declared that there are no other relationships or activities that could appear to have influenced the submitted work.

\section{References}

1. Gudrunardottir T, Morgan A, Lux A, et al.: Consensus paper on post-operative pediatric cerebellar mutism syndrome: the Iceland Delphi results. Childs Nerv Syst. 2016, 32:1195-1203. 10.1007/s00381-016-3093-3

2. Catsman-Berrevoet C, Van Dongen HR, Mulder P, Paquier GyP, Lequin M: Tumour type and size are high risk factors for the syndrome of "cerebellar" mutism and subsequent dysarthria. J Neurol Neurosurg Psychiatry. 1999, 67:755-757. 10.1136/jnnp.67.6.755

3. Silva JAG, Atayde SA, Brito JCF, Nóbrega PV, Neves VD: Mutismo cerebelar transitório: relato de dois casos. [Article in Portuguese]. Arq Neuropsiquiatr. 1999, 57:1011-1016. 10.1590/S0004-282X1999000600019

4. Nicita F, Paiano M, Liberatore M, et al.: Sudden benzodiazepine-induced resolution of post-operative pediatric cerebellar mutism syndrome: a clinical-SPECT study. Acta Neurochir. 2017, 159:475-479. 10.1007/s00701-016-3059-y

5. Pitsika M, Tsitouras V: Cerebellar mutism. J Neurosurg Pediatr. 2013, 12:604-614. 10.3171/2013.8.PEDS13168

6. van Baarsen KM, Grotenhuis JA: The anatomical substrate of cerebellar mutism. Med Hypotheses. 2014, 82:774-780. 10.1016/j.mehy.2014.03.023

7. Küper M, Timmann D: Cerebellar mutism. Brain Lang. 2013, 127:327-333. 10.1016/j.bandl.2013.01.001

8. da Silveira HG, Pinto MBP, Rodrigues RGB, Ferreira MAT: Síndrome de fossa posterior: relato de caso . Revista Científica de Saúde do Centro Universitário de Belo Horizonte. 2019, 12:6-9.

9. Arnts H, van Erp WS, Lavrijsen JCM, van Gaal S, Groenewegen HJ, ven den Munckhof P: On the pathophysiology and treatment of akinetic mutism. Neurosci Biobehav Rev. 2020, 112:270-278. 10.1016/j.neubiorev.2020.02.006

10. Tovar-Spinoza Z, Choi H: Magnetic resonance-guided laser interstitial thermal therapy: report of a series of pediatric brain tumors. J Neurosurg Pediatr. 2016, 17:723-733. 10.3171/2015.11.PEDS15242

11. Yang L, Jia G, Li B, Lei G, Sun R: Encephalitis lethargica with isolated substantia nigra lesions followed by a second encephalitis in a child with humoral immunodeficiency. Pediatr Neurol. 2015, 53:519-522. 10.1016/j.pediatrneurol.2015.03.030

12. Suga K, Goji A, Shono M, et al.: Mumps encephalitis with akinesia and mutism. Pediatr Int. 2015, 57:721724. 10.1111/ped.12581

13. Kamasak T, Sahin S, Eyuboglu I, Reis GP, Cansu A: Síndrome talâmica paramediana bilateral após infecção . Pediatr Neurol. 2015, 52: 235-238. 10.1016/j.pediatrneurol.2014.09.012

14. Pinheiro JAB, das Neves FWB, de Andrade FD, Paixão JRR, do Rego Barros R, dos Santos Braga R, de Moraes JL: Mutismo cerebelar transitório após cirurgia para tumor de fossa posterior em criança . J Bras Neurocir. 2018, 23:337-341. 10.22290/jbnc.v23i4.1231

15. Erşahin Y, Mutluer S, Cağli S, Duman Y: Cerebellar mutism: report of seven cases and review of the literature. Neurosurgery. 1996, 38:60-65. 10.1097/00006123-199601000-00015

16. Van dongen HR, Catsman-berrevoets CE, Van mourik M: The syndrome of 'cerebellar' mutism and subsequent dysarthria. Neurology. 1994, 44:2040-2046. 10.1212/WNL.44.11.2040

17. Kotil K, Eras M, Akçetin M, et al.: Cerebellar mutism following posterior fossa tumor resection in children . Turk Neurosurg. 2008, 18:89-94.

18. Pollack IF, Polinko P, Albright LA, Towbin R, Fitz C: Mutism and pseudobulbar symptoms after resection of posterior fossa tumors in children: incidence and pathophysiology. Neurosurgery. 1995, 37:885-893. 10.1227/00006123-199511000-00006

19. Akshoomoff N, Courchesne E: A new role for the cerebellum in cognitive operations . Behav Neurosci. 1992, 106:731-738. 10.1037/0735-7044.106.5.731

20. Teive H, Arruda W: Cerebellum and cognition Henrietta Leiner's contribution. Historical note . Dement 


\section{Cureus}

Neuropsychol. 2016, 10:358-360. 10.1590/s1980-5764-2016dn1004017

21. Rostomily R, Berger M, Ojemann G, Ojemann GA, Lettich E: Postoperative deficits and functional recovery following removal of tumors involving the dominant hemisphere supplementary motor area. J Neurosurg. 1991, 75:62-68. 10.3171/jns.1991.75.1.0062

22. Schmahmann JD, Sherman JC: The cerebellar cognitive affective syndrome. Brain. 1998, 121:561-579. 10.1093/brain/121.4.561

23. Gudrunardottir T, Sehested A, Juhler M, Schmiegelow K.: Cerebellar mutism. Childs Nerv Syst. 2010, 27:355363. 10.1007/s00381-010-1328-2

24. Habas C: Functional imaging and the cerebellum: recent developments and challenges. Editorial . Cerebellum. 2012, 11:311-313. 10.1007/s12311-012-0375-5

25. Toescu S, Hettige S, Phipps K, et al.: Post-operative paediatric cerebellar mutism syndrome: time to move beyond structural MRI. Childs Nerv Syst. 2018, 34:2249-2257. 10.1007/s00381-018-3867-x

26. Chao J, Liu C, Shetty N, Ushma S: Postoperative pediatric cerebellar mutism after posterior fossa surgery: a case report. A A Case Rep. 2017, 8:213-215. 10.1213/XAA.0000000000000467

27. Mussi A, Rhoton A: Telovelar approach to the fourth ventricle: microsurgical anatomy . J Neurosurg. 2000, 92:812-823. 10.3171/jns.2000.92.5.0812

28. Tanriover N, Ulm A, Rhoton A, Yasuda A: Comparison of the transvermian and telovelar approaches to the fourth ventricle. J Neurosurg. 2004, 101:484-498. 10.3171/jns.2004.101.3.0484 